\title{
The permeation of acamprosate is predominantly caused by paracellular diffusion across Caco-2 cell monolayers: A paracellular modelling approach
}

\author{
Irina E. Antonescu ${ }^{1}$, Karina F. Rasmussen ${ }^{2 \dagger \dagger}$, Sibylle Neuhoff ${ }^{3}$, Xavier Fretté ${ }^{4}$, Maria Karlgren ${ }^{5}$, Christel A. S. Bergström ${ }^{5}$, \\ Carsten Uhd Nielsen ${ }^{1}$ and Bente Steffansen ${ }^{*}{ }^{1 \dagger}$ \\ ${ }^{1}$ Department of Physics, Chemistry \& Pharmacy, Faculty of Science, University of Southern Denmark, DK-5230 Odense, \\ Denmark \\ ${ }^{2}$ Department of Pharmacy, University of Copenhagen 2100 Copenhagen Denmark \\ ${ }^{3}$ Certara UK Ltd., Simcyp Division, Sheffield, UK \\ ${ }^{4}$ Department of Chemical Engineering, Biotechnology and Environmental Technology, Faculty of Engineering, University of \\ Southern Denmark, DK-5230 Odense, Denmark \\ ${ }^{5}$ Department of Pharmacy, Uppsala University, Sweden
}




\section{S1. Quantification of compounds.}

\section{S1.1. Acamprosate}

a) Samples from the studies on DSMZ Caco-2 cell line. The aliquoted samples from the permeability experiments were centrifuged at $14000 \mathrm{rpm}$ and $5^{\circ} \mathrm{C}$ for 10 minutes. The supernatant was transferred to HPLC vials with caps. The donor samples at $\mathrm{t}=0 \mathrm{~min}$ and $\mathrm{t}=120 \mathrm{~min}$ and the higher concentration acceptor samples were diluted to $0.1-20 \mu \mathrm{M}$ acamprosate, using permeability buffer as diluent. Acamprosate was quantified using a new LC/MS-MS method specifically developed for acamprosate. A tandem 6460 Triple Quad MS-MS system (Agilent Technologies) with electrospray ionization (ESI) and an orthogonal ion source design, attached to a 1200 Series Infinity LC system (Agilent Technologies) equipped with a binary pump. Data acquisition was done using the MassHunter Qualitative Analysis 8.07 software package (Agilent). The chromatographic separation was carried on an XBridge ${ }^{\mathrm{TM}}$ Amide column $(2.1 \times 100 \mathrm{~mm}, 3.5 \mu \mathrm{m})$. The column and auto sampler tray temperatures were set to $40^{\circ} \mathrm{C}$ and $24^{\circ} \mathrm{C}$, respectively. The mobile phases used were $20.0 \mathrm{mM}$ ammonium formate and $0.25 \%$ formic acid in water (mobile phase A) and 90:10 acetonitrile:water (mobile phase B). The injection volume was $1 \mu \mathrm{L}$. The separation was done with a flow of $0.4 \mathrm{~mL} / \mathrm{min}$ in a linear gradient mode starting from $3 \%$ to $50 \%$ mobile phase A in 3 min, and then back to $3 \%$ mobile phase A from 3 to 4 minutes, to obtain the baseline separation of acamprosate at a retention time of $\sim 1.6$ minutes. The total runtime per sample was 7 minutes. The mass spectrometer was operated in the multiple reaction monitoring mode (MRM) and the sample introduction and ionization were done in the negative ion $[\mathrm{M}-\mathrm{H}]^{-}$mode. The mass transition was selected as $m / z$ $180 \rightarrow 80$ for acamprosate. The fragmentor voltage, collision energy and cell accelerator voltage were optimized to 100,24 and $7 \mathrm{~V}$, respectively, while the dwell time was set to $200 \mathrm{~ms}$ per transition. A stock solution of $1.0 \mathrm{mM}(180.2 \mu \mathrm{g} / \mathrm{mL}) \mathrm{acamprosate}$ was prepared by dissolving the appropriate amount of acamprosate calcium in permeability buffer. Independent triplicate calibration standards were prepared from the acamprosate stock solution at the concentration levels of 0.1-20.0 $\mu \mathrm{M}(18-3600$ $\mathrm{ng} / \mathrm{mL}$ ) and QC standards at the concentration levels of 0.5 and $5.0 \mu \mathrm{M}$ (or 90 and $900 \mathrm{ng} / \mathrm{mL}$ ) acamprosate, using permeability buffer as diluent. All solutions were stored at refrigerator conditions $2-8^{\circ} \mathrm{C}$ until or in between analyses.

b) Samples from studies on ATCC Caco-2 cell line. The samples from the apical and basolateral acceptor chambers were diluted 1: 3 and 1: 1, respectively, with a solution of $50 \mathrm{nM}$ warfarin in 60:40 acetonitrile: water (IS solution). The cut filters with cell monolayers were treated with $200 \mu \mathrm{L}$ IS solution and vortexed for 3-4 minutes. The donor samples were diluted with the IS solution to a final concentration of 2-8 $\mu \mathrm{M}$ acamprosate. All samples were centrifuged at $3500 \mathrm{rpm}$ and $5^{\circ} \mathrm{C}$ for 20 min. The supernatant from each sample was transferred to 96-well plates. Acamprosate was quantified using a Waters Xevo Triple-Quadrupole MS with electrospray ionization (Zspray) coupled to an Acquity UPLC (Waters, Milford, MA). The system control was done with MassLynx software and data analysis with TargetLynx software. The chromatographic separation was carried out on an Acquity UPLC HSS T3 column, 2.1x50 mm $(1.8 \mu \mathrm{m})$ over a 2-minute gradient, with a flow rate of 0.5 $\mathrm{mL} /$ minute, at $60^{\circ} \mathrm{C}$. The sample injection volume was $10 \mu \mathrm{L}$ and the autosampler temperature was $10^{\circ} \mathrm{C}$. Mobile phase A consisted of $5 \%$ acetonitrile and $0.1 \%$ formic acid in water and mobile phase B contained $0.1 \%$ formic acid in acetonitrile. The chromatographic run comprised of a flow of $95 \%$ mobile phase A and 5\% mobile phase B for the first 0.5 minutes, followed by a linear increase of mobile phase B from 5\% to 95\% from 0.5-1.2 minutes, then a hold of 95\% mobile phase B from 1.2 to 1.6 minutes, and finally a linear return to initial conditions from 1.6 to 2 minutes. Acamprosate was separated at an elution time of $\sim 0.36$ minutes, while IS eluted at $\sim 1.6$ minutes. The mass spectrometer was operated in MRM, negative ion mode. The ion spray temperature was $500^{\circ} \mathrm{C}$. The cone voltage (CV) was optimized to $20 \mathrm{~V}$ for IS and $38 \mathrm{~V}$ for acamprosate, while the collision energy (CE) was optimized to $24 \mathrm{~V}$ for both IS and acamprosate. Quantification was done by multiple reaction monitoring of parent and daughter ions. The mass transitions used were $m / z \quad 179.90 \rightarrow 80.00$ and $309.15 \rightarrow 163.01$ for acamprosate and IS, respectively, with a dwell time of $160 \mathrm{~ms}$ per transition. A stock solution of $50.0 \mathrm{mM}(9.06 \mathrm{mg} / \mathrm{mL})$ acamprosate was prepared by dissolving the appropriate amount of acamprosate calcium in permeability buffer. Independent triplicate calibration standards 
were prepared from the acamprosate stock solution at the concentration levels of $0.003-10.0 \mu \mathrm{M}(0.57-1812 \mathrm{ng} / \mathrm{mL}) \mathrm{and} \mathrm{QC}$ standards at the concentration levels of $3.16 \mathrm{nM}, 60 \mathrm{nM}, 600 \mathrm{nM}$ and $6 \mu \mathrm{M}$ (or 0.57, 10.87, $108.72 \mathrm{and} 1087.20 \mathrm{ng} / \mathrm{mL}$ ) acamprosate, using permeability buffer as diluent. All solutions were stored at refrigerator conditions $2-8^{\circ} \mathrm{C}$ until or in between analyses. The method validation was done according to the U.S. Food and Drug Administration (FDA) Bioanalytical Method Validation guidance for industry. The validated parameters were selectivity, sensitivity, linearity, accuracy, precision and dilution integrity. Selectivity. Blank cell matrix samples showed a response of $17.35 \pm 3.46 \%$ (mean \pm S.D., $n=4)$ of the lower limit of quantification (LLOQ) at the retention time of the acamprosate, therefore we can assume the components of the cell matrix do not interfere with the detection of acamprosate. The transport buffer blank and zero calibration blank (containing only the internal standard warfarin) had a signal $<20 \%$ of LLOQ. We have not evaluated interference from metabolites as acamprosate is not metabolized in enterocytes. Sensitivity. LLOQ for acamprosate was $3.16 \mathrm{nM}(0.57 \mathrm{ng} / \mathrm{mL})$. This amount was quantified with an accuracy of $16.06 \%$ from nominal concentration and a precision of $10.78 \%(\mathrm{n}=5$ replicates). Linearity. The triplicate standard curve contained 9 concentration levels and was linear for the range of $3.16 \mathrm{nM}-10.00 \mu \mathrm{M}(0.57-1802 \mathrm{ng} / \mathrm{mL})$, $\mathrm{R}^{2}=0.9968$. The back calculated average concentrations of all non-zero calibrators were within $85-115 \%$ of their nominal concentrations except LLOQ who was between 80-120\% of its nominal concentration. Accuracy and precision. The accuracy and precision of the method was controlled by measuring QC samples prepared independently from the calibration standards, with a final concentration of 3.16 (LLOQ), 60.00 (low-range QC), 600.00 (mid-range QC) and 6000.00 (high range QC) nM acamprosate, in 5 replicates and measured in at least 3 independent runs. The intra-run accuracy for low-, mid- and high-range QC samples was between 2.02-8.84 \% while the precision was 4.15-8.88\%. The inter-run measurements had an accuracy of $6.12-11.33 \%$ and a precision of 6.90-11.59\%. Dilution integrity. $200.00 \mu \mathrm{M}$ standards diluted $1 / 100$ gave back calculated concentrations in the range of $85-115 \%$ of their nominal concentration, and a CV of $5.93 \%$.

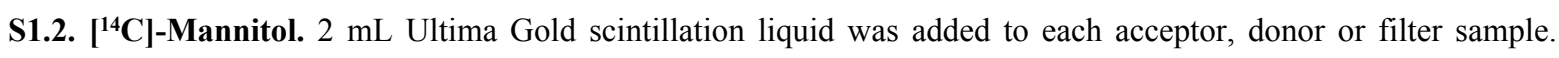
Samples were then mixed thoroughly and the total radioactivity (decays per minute, dpm) was measured by liquid scintillation counting on a Perkin Elmer TriCarb 4910 TR (Boston, MA, USA). A blank measurement was performed on the permeability buffer to subtract the background dpm from the total dpm. The theoretical concentration and measured radioactivity of the donor samples were used to calculate the compound concentration in the samples, by using Equation S2.

$$
\text { pmol }\left[{ }^{14} C\right]-\text { mannitol }_{\text {sample }}=\frac{p m o l\left[{ }^{14} C\right]-\text { mannitol }_{\text {donor }}}{d p m_{\text {donor }}} \times d p m_{\text {sample }} \text { Equation S2 }
$$

where pmol $\left[14_{C}-\text { mannitol }\right]_{\text {donor }}$ is the theoretical amount of $\left[{ }^{14} \mathrm{C}\right]$-mannitol in the $20 \mu \mathrm{L}$ donor, $d p m_{\text {donor }}$ is the total radioactivity measured in the same donor sample, pmol $\left[14_{C}\right]-$ mannitol $_{\text {sample }}$ is the calculated amount of $\left[{ }^{14} \mathrm{C}\right]-$ mannitol in the test sample and $d p m_{\text {sample }}$ is the total radioactivity of the test sample.

S1.3. Lucifer yellow and fluorescein sodium. The donor and acceptor samples from the lucifer yellow and fluorescein sodium permeability experiments were transferred to 96-well black NUNC plates with a transparent bottom and quantified with a FLUOStar Omega plate reader (BMG Labtech), excitation 485 $\pm 12 \mathrm{~nm}$, emission $520 \mathrm{~nm}$. Triplicate independent calibration standard solutions were prepared in the concentration range of $0.001-40 \mu \mathrm{M}$ for fluorescein sodium and $0.5-105 \mu \mathrm{M}$ for lucifer yellow. Separate fluorescein sodium quality control (QC) samples were prepared at 0.5 and $5 \mu \mathrm{M}$ concentration levels and were measured in parallel with the calibration standards. The same QC samples were used as external standards for each set of analyzed samples. The fluorescein sodium experiment samples, standards and QC samples were diluted 1:5 with a $\mathrm{NaOH}$ solution $\mathrm{pH}=9$ (end $\mathrm{pH} \sim 8.5$ ) to increase the sensitivity of the analysis. All the samples, standards and QC samples were stored in dark containers at refrigerator conditions $\left(2-8^{\circ} \mathrm{C}\right)$ until or in between analyses. The calibration of sodium fluorescein at $\mathrm{pH}$ $\sim 8.5$ had a limit of detection (LOD) of $1 \mathrm{nM}$ and a linear range of $5 \mathrm{nM}-40 \mu \mathrm{M}(1.9 \mathrm{ng} / \mathrm{mL}-15.1 \mu \mathrm{g} / \mathrm{mL}), \mathrm{R}^{2}=0.997$. 
Quenching of the fluorescent signal was observed above $40 \mu \mathrm{M}$. For Lucifer yellow at $\mathrm{pH} \sim 7.4$, the LLOQ was $0.5 \mu \mathrm{M}$ and a linear range between $0.5 \mu \mathrm{M}-105.0 \mu \mathrm{M}(0.23-48 \mu \mathrm{g} / \mathrm{mL}), \mathrm{R}^{2}=0.998$, and quenching was observed over $105 \mu \mathrm{M}$.

S1.4. Atenolol. The samples from the donor and acceptor compartment were centrifuged at $14000 \mathrm{rpm}$ and $5^{\circ} \mathrm{C}$ for 10 minutes. The supernatant was transferred to HPLC vials with caps. The donor samples at $\mathrm{t}=0 \mathrm{~min}$ and $\mathrm{t}=120$ min and the higher concentration acceptor samples were diluted 1:100 with permeability buffer to $\sim 15 \mu \mathrm{M}$ atenolol. Atenolol was analyzed by chromatographic separation with a XTerra ${ }^{\mathrm{TM}}$ MS C18 column $(2.1 \times 100 \mathrm{~mm}, 3.4 \mu \mathrm{m})$ The mobile phase was composed of 50:50 (v/v) methanol/water containing $0.1 \%$ trifluoracetic acid. The injection volume was $20 \mu \mathrm{L}$. The separation was done with a flow of $0.25 \mathrm{~mL} / \mathrm{min}$ to obtain the baseline separation of atenolol at a retention time of $\sim 5.8$ minutes. The total runtime per sample was 10 minutes. The separated atenolol was quantified with a Shimadzu RF-20A XS fluorescence detector, excitation $229 \mathrm{~nm}$, emission $309 \mathrm{~nm}$. Data acquisition was done using the LabSolutions software package. A stock solution of $10.0 \mathrm{mM}$ (2.66 $\mathrm{mg} / \mathrm{mL}$ ) atenolol was prepared by dissolving the appropriate amount of atenolol in permeability buffer. Independent triplicate calibration standards were prepared from the stock solution diluted first to $100 \mu \mathrm{M}$ and then to 8 concentration levels between 0.1-20.0 $\mu \mathrm{M}$. QC samples were prepared at the concentration levels of 0.8 (low-range QC), 3 (mid-range QC) and 8 (high range QC) $\mu \mathrm{M}$ atenolol, using permeability buffer as diluent. The QC samples were run in 5 replicates in 3 independent runs. All solutions were stored at $-20^{\circ} \mathrm{C}$ until or in between analyses. The standard curve was linear for the range of $0.1-15 \mu \mathrm{M}(0.57-$ $1802 \mathrm{ng} / \mathrm{mL}$ ), $\mathrm{R}^{2}=0.9993$. The back calculated average concentrations of all standards were within $85-115 \%$ of their nominal concentrations except LLOQ $(0.1 \mu \mathrm{M})$ who was between $80-120 \%$ of its nominal concentration. The accuracy for low-, midand high-range QC samples was between 1.47-11.23\% while the precision was $0.72-1.53 \%$. 
a

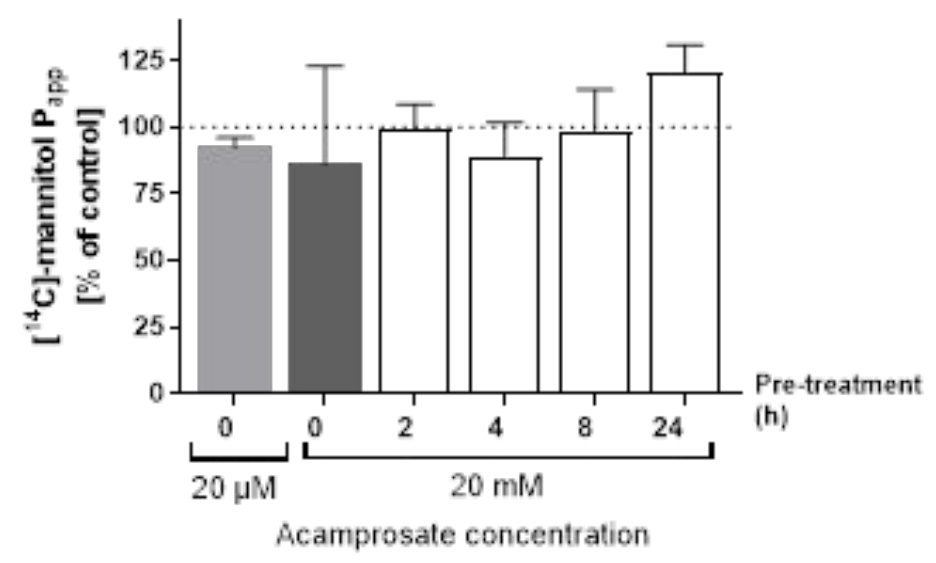

b

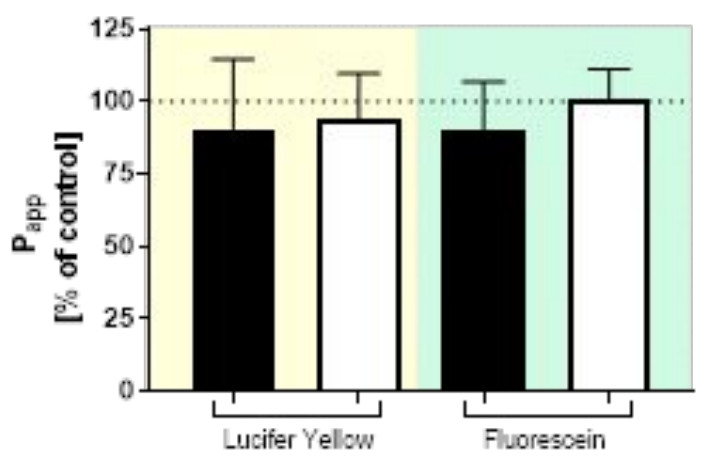

c

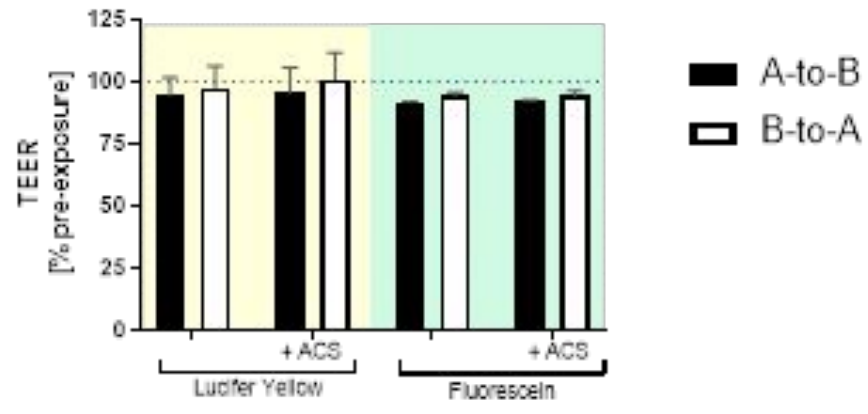

Figure S2. (a) Relative $\mathrm{P}_{\text {app }}$ of $7 \mu \mathrm{M}\left[{ }^{14} \mathrm{C}\right]$-mannitol across Caco-2 monolayers in the presence of $20 \mu \mathrm{M}$ or $20 \mathrm{mM}$ acamprosate applied concomitantly (grey bars) or across monolayers pre-treated with $20 \mathrm{mM}$ acamprosate for 2, 4, 8 or 24 hours (white bars). Results are presented as $\%$ of $\left[{ }^{14} \mathrm{C}\right]$-mannitol $\mathrm{P}_{\text {app }}$ in the absence of acamprosate (control). The bars represent the mean \pm SD of 3 replicate results. (b) Relative $\mathrm{P}_{\text {app }}$ of $100 \mu \mathrm{M}$ lucifer yellow or $26.5 \mu \mathrm{M}$ fluorescein across Caco2 monolayers in the presence of $20 \mathrm{mM}$ acamprosate in the A-B (black bars) or B-A (white bars) permeability direction.

Results are presented as \% of lucifer yellow or fluorescein $\mathrm{P}_{\text {app }}$ in the absence of acamprosate (control). The bars represent the mean \pm SD of 3 replicate results. The dotted line represents $100 \%$ of control. (c) Changes in monolayer TEER $\left(\Omega \cdot \mathrm{cm}^{2}\right)$ after permeation of $100 \mu \mathrm{M}$ lucifer yellow or $26.5 \mu \mathrm{M}$ fluorescein in the A-B (black bars) or B-A (white bars) permeability directions, either in the presence or absence of $20 \mathrm{mM}$ acamprosate (ACS). Results are shown as $\%$ of control (pre-exposure TEER, after buffer-preincubation and before application of donor solution) and represent mean $\pm \mathrm{SD}$ of 3 replicate results. The dotted line represents $100 \%$ of control. 